\title{
A hospital based cross-sectional study to assess various types of non-glaucomatous optic neuropathies
}

\author{
${ }^{1}$ Palpa Lions Lacoul Eye Hospital, Palpa, Nepal \\ ${ }^{2}$ Shree Medical and Technical College, Bharatpur, Nepal \\ ${ }^{3}$ Birat Eye Hospital,Biratnagar, Nepal \\ ${ }^{4}$ National Institute of Neuro and Allied Sciences, Kathmandu, Nepal \\ ${ }^{5}$ Bascom Palmer Eye Institute,Miami, USA
}

Araniko Pandey ${ }^{*}$, Shakti Shrestha ${ }^{2}$, Arjun Malla Bhari ${ }^{3}$, Lekh Jung Thapa ${ }^{4}$, Delia DeBuc ${ }^{5}$ and Anadi Khatri ${ }^{3}$

\begin{abstract}
Background: There is paucity of data on non-glaucomatous optic neuropathy (NGON) from low- and middle-income countries (LMIC). This study was conducted with a purpose to collect a variety of NGON in the adult population.

Methods: This was a hospital-based cross-sectional study conducted between June 2016 - December 2016. All adult patients diagnosed with NGON were included. A detailed history taking was done followed by, best corrected visual acuity testing, pupillary examination, color vision, contrast sensitivity, slit-lamp bio-microscopy and fundus evaluation under mydriasis. Visual field examination and brain/orbit imaging were performed according to the necessity of the cases. Data were analyzed using IBM-SPSS version 20.

Results: There were 130 patients with NGON, but only 117 cases that had adequate data to make a diagnosis were included in our study. The total number of eyes with NGON in our study was 166 . The commonest diagnosis was non-arteritic ischemic optic neuropathy (45/117). Other common causes were traumatic optic neuropathy (16/117) and optic neuritis (11/117) subsequently. Alcohol-induced optic neuropathy (3/117) and Leber's hereditary optic neuropathy (5/117) were also suspected. They were diagnosed on the basis of most relevant clinical findings and exclusion of other causes. Two cases of pregnancy-induced pituitary apoplexy were also diagnosed. Patients with inadequate evidence to make a diagnosis were grouped as; bilateral disc edema (2), unilateral optic atrophy (2) and papilledema (19).
\end{abstract}

Conclusion: The emerging burden of NGON in LMIC could not be neglected. Further research is necessary to understand the causative factors for underdiagnosis of NGON in LMIC.

\section{Introduction}

Clinical features such as the presence of visual field (VF) loss, optic disc cupping and vision loss in glaucomatous optic neuropathy overlaps with non-glaucomatous optic neuropathies (NGON). However, distinct differences between glaucomatous optic neuropathy and NGON are encountered in clinical practice. Etiological factors of nonglaucomatous optic neuropathy (NGON) can be hereditary, inflammatory, compressive, vascular, infiltrative, traumatic, toxic and nutritional [1-3].

This etiological factor's heterogeneity along with the overlapping clinical features in glaucomatous optic neuropathy points to the crucial need to determine the framework of an exposed optic neuropathy so that clinicians can consider a proper workup that will lead to appropriate intervention and follow-up [4-6].

According to two major blindness surveys done in Nepal, almost 30 years apart, cataract was found to be the most prevalent cause. Blindness due to NGON probably felt under miscellaneous or posterior segment diseases, which were not considered any further [3,7].

A review of the literature through various databases showed only a few articles that could establish the actual burden of optic neuropathies in Nepal $[8,9]$. A search for the global database for NGON using keywords like; optic neuropathy and optic atrophy, also showed inadequate evidence. Most studies only focused on individual causes of NGON and, just a few studies showed the distribution of NGON in Nigeria, China, and India [10-14].

Considering that there are clinical cases in which optic disc changes evolve secondary to non-glaucomatous processes, it is essential to track the actual burden of optic neuropathies. This study was conducted with a purpose to collect a variety of non-glaucomatous optic neuropathies in the adult population, that presented at a tertiary level eye care center in Nepal. Identifying non-glaucomatous optic nerve disorders from the glaucomatous disease cannot only save many lives but also avoid spending significant resources (e.g., time and money) that would have been spent overseeing an eye disorder that is neither there nor developing.

${ }^{*}$ Correspondence to: Anadi Khatri, Birat Eye Hospital, Biratnagar, Nepal. Tel: +9779841767205, +9779810400414; E-mail: anadikc @gmail.com

Key words: optic nerve head, optic neuropathy, non-glaucomatous optic neuropathy

Received: December 14, 2018; Accepted: December 24, 2018; Published: December 28, 2018 


\section{Methods}

A hospital-based cross-sectional study was conducted between June 2016 - December 2016. The study protocol was approved by the Institutional Review Board at the Lumbini Eye Institute in Nepal.

Adult patients of any sex with optic neuropathies were included in the study. All other patients diagnosed or suspected to have glaucoma and other causes of disc edema, which involved retinal vascular occlusions, posterior scleritis, neuroretinitis or retinopathies were excluded. Also, those patients with incomplete evidence to approach for the diagnosis were excluded.

Examination included the detailed history, best corrected visual acuity (BCVA), pupillary examination, color vision (Pseudoisochromatic Chart of Ishihara), contrast sensitivity (Pelli-Robson Chart), slit-lamp bio-microscopy and fundus evaluation under mydriasis. Visual field examination (Humphrey Field Analyzer) and brain/orbit imaging were performed according to the necessity of the case.

Descriptive statistics were obtained using IBM-SPSS version 20 (IBM Corporation, Armonk, NY, USA).

\section{Results}

There were altogether 130 patients with NGON, but only 117 cases that had adequate data to make a diagnosis were included in our study. The total number of eyes with NGON in our study was 166 .

Majority of the patients were male (69/117), and the most prevalent age group was 45-64 yrs (51/117) ranging from 17 years to 78 years of age. Both eyes were involved in 49/117 patients. Out of 166 eyes with NGON, 35 and seven eyes had a significantly decreased vision of $<1 / 60$ PL and NPL, respectively (Table 1).

A wide variety of patients with NGON were diagnosed. The most frequent primary diagnosis was non-arteritic ischemic optic neuropathy (NAION, Figure 1) (45/117) and other common causes were traumatic optic neuropathy (TON) (16/117) and optic neuritis (11/117), subsequently. Alcohol-induced optic neuropathy (AION) (3/117) and Leber hereditary optic neuropathy (LHON) (5/117) were also suspected. They were diagnosed by most relevant clinical findings and through the exclusion of other causes. Two cases of pregnancyinduced pituitary apoplexy were also diagnosed, which was confirmed after consultation with a neurologist (Table 2).

Cause of NGON could not be found in 22/117 cases, and they were grouped under papilledema (17; acute - 12 and chronic - 7) and optic atrophy (3; unilateral - 2 and bilateral - 1).

\section{Leber hereditary optic neuropathy}

Five cases of LHON were suspected and were approached to the diagnosis based on clinical findings only, due to unavailability of gene analysis in our setting. Among those who were diagnosed with LHON, 2 cases of a mother (aged 40 years) and a son (20 years old) presented with a progressive, painless decreased vision for 14 years (mother) and three years (son). Mother had BCVA of 6/60 in both eyes (OU). Her posterior segment examination showed optic atrophy with clearly demarcated margins, OU. Son had BCVA of 3/60 in the right eye (OD) and 6/12 in the left eye (OS). He had a relative afferent pupillary defect (RAPD), with red-green color vision defect OU and impaired contrast sensitivity, OD only. Posterior segment evaluation showed optic atrophy with clear margins, OD and healthy optic nerve head, OS. MRI of the brain was within normal limits in both cases.
Table 1. Profile of patients with nonglaucomatous optic neuropathy

\begin{tabular}{|l|c|c|}
\hline Categories (N=117) & \multicolumn{2}{|c|}{ Frequency } \\
\hline Age (Years) & 11 & 9.4 \\
\hline $15-24$ & 47 & 40.2 \\
\hline $25-44$ & 51 & 43.6 \\
\hline $45-64$ & 8 & 6.8 \\
\hline$>=65$ & \multicolumn{2}{|c|}{} \\
\hline Gender & 69 & 59 \\
\hline Male & 48 & 41 \\
\hline Female & \multicolumn{2}{|c|}{} \\
\hline Laterality of the affected eye & 31 & 26.5 \\
\hline Right & 37 & 31.6 \\
\hline Left & 49 & 41.9 \\
\hline Both & & \\
\hline BCVA of affected eyes (N=166) & 45 & 27.1 \\
\hline $6 / 6-6 / 18$ & 41 & 24.7 \\
\hline$<6 / 18-6 / 60$ & 13 & 7.8 \\
\hline$<6 / 60-3 / 60$ & 25 & 15.1 \\
\hline$<3 / 60-1 / 60$ & 35 & 21.1 \\
\hline$<1 / 60-P L$ & 7 & 4.2 \\
\hline NPL & & \\
\hline
\end{tabular}

BCVA, Best corrected visual acuity

PL, Perception of light

NPL, No perception of light
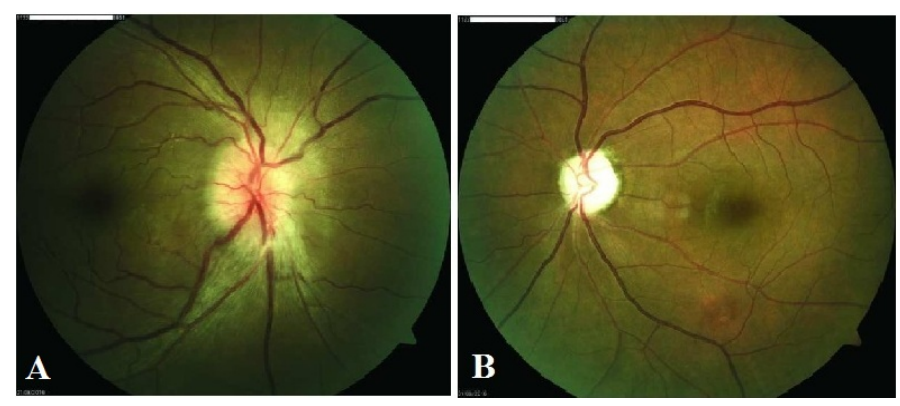

Figure 1. Fundus photograph of nonarteritic ischemic optic neuropathy showing $(1 \mathrm{~A})$ disc edema with loss of optic cup, right eye and (1B) fellow eye with optic atrophy with "disc at risk", left eye. The patient was a 32 years male; best corrected visual acuity 1/60 OD, 6/36 OS. Magnetic resonance imaging was normal

Table 2. Types of non-glaucomatous optic neuropathy ( $\mathrm{N}=117)$

\begin{tabular}{|l|c|c|}
\hline Diagnosis & Frequency & Percent (\%) \\
\hline Compressive optic neuropathy & 5 & 4.2 \\
\hline NAION & 45 & 38.4 \\
\hline Optic atrophy & 3 & 2.5 \\
\hline Traumatic optic neuropathy & 16 & 13.6 \\
\hline Optic neuritis & 11 & 9.4 \\
\hline Alcohol-induced optic neuropathy & 3 & 2.5 \\
\hline Leber hereditary optic neuropathy & 5 & 4.2 \\
\hline Idiopathic intracranial hypertension & 7 & 5.9 \\
\hline Pituitary apoplexy & 2 & 1.7 \\
\hline Papilledema & 19 & 16.2 \\
\hline Ethambutol-induced optic neuropathy & 1 & 0.8 \\
\hline
\end{tabular}

NAION, Nonarteritic ischemic optic neuropathy

\section{Alcohol-Induced optic neuropathy}

There were 3 cases, suspected to have alcohol-induced optic neuropathy (Figure 2). These cases were also diagnosed on the basis of exclusion and relevant clinical findings which especially included a personal history of chronic alcohol consumption. 


\section{Pituitary apoplexy}

A rare case of NGON was observed in 22 years old female who had a sudden loss of vision in both eyes; 10 days postpartum. She had a history of seizure during pregnancy for which she was admitted in ICU. Her child could not survive after 29 days of birth. At presentation, her BCVA was PL, OD and NPL, OS. She had mid-dilated ill sustained pupillary response to light. Posterior segment examination showed optic atrophy with bilateral disc edema "champagne cork appearance" and hard exudates over the parapapillary region (Figure 3). MRI of the brain showed space occupying lesion. Diagnosis of pituitary apoplexy was confirmed in consultation with a neurologist.

\section{Compressive optic neuropathy}

Out of 30 patients who were reviewed with brain/orbit imaging, ten patients had a significant finding with lesions that could support a compressive cause (5/117) for optic neuropathy (Table 3). Other important vision/life-threatening diseases were also identified viz; pituitary apoplexy, pituitary adenoma, craniopharyngioma, raised ICP with enlarged ventricles, additional intracranial space occupying lesion (SOL) and optic neuritis.
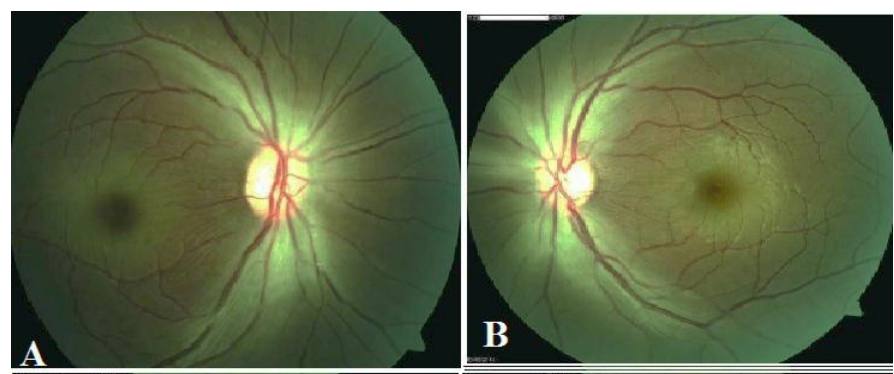

A

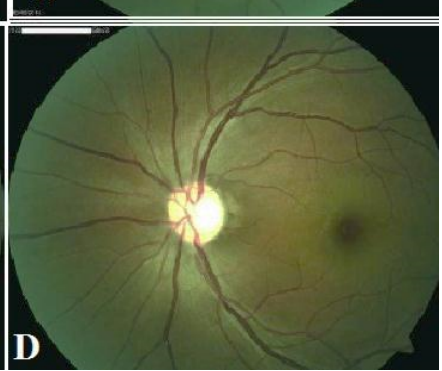

Figure 2. Fundus photograph of alcohol-induced optic neuropathy showing (2A) polar disc edema and choroidal folds extending from temporal disc margin, right eye and $(2 \mathrm{~B})$ left eye. A 35yrs alcoholic male patient with sudden loss of vision, intense sweating and tremors at presentation. Thiamine and folic acid supplement with abstinence of alcohol in consultation with a psychiatrist resulted in improvement in vision and resolved disc edema on follow up, right eye (2C) and left eye (2D)
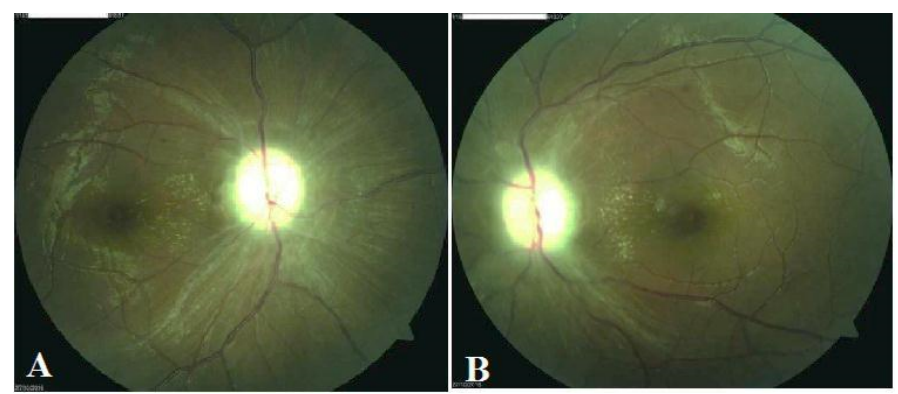

Figure 3. Fundus photograph of pituitary apoplexy showing (3A) optic atrophy with disc edema "champagne cork appearance", right eye and (3B) left eye
Table 3. Patients diagnosed with compressive cause for optic neuropathy

\begin{tabular}{|c|c|c|c|l|l|}
\hline SN & $\begin{array}{c}\text { Age } \\
(\mathbf{y r s}) / \mathbf{S e x}\end{array}$ & $\begin{array}{c}\text { BCVA } \\
\text { (OD) }\end{array}$ & $\begin{array}{c}\text { BCVA } \\
\text { (OS) }\end{array}$ & Diagnosis & Remarks \\
\hline 1 & $50 / \mathrm{M}$ & $3 / 60$ & $1 / 60$ & $\begin{array}{l}\text { Pituitary } \\
\text { macroadenoma }\end{array}$ & \\
\hline 2 & $42 / \mathrm{F}$ & $\mathrm{HM}$ & $6 / 9$ & $\begin{array}{l}\text { Malignant } \\
\text { chiasmal } \\
\text { infiltration }\end{array}$ & $\begin{array}{l}\text { Destructive nasopharyngeal } \\
\text { lesion extending to sella/parasella } \\
\text { (Imaging) }\end{array}$ \\
\hline 3 & $50 / \mathrm{M}$ & $6 / 36$ & $\mathrm{HM}$ & Compressive & $\begin{array}{l}\text { Surgery for IC SOL done 4 months } \\
\text { back (No further information) }\end{array}$ \\
\hline 4 & $60 / \mathrm{M}$ & $6 / 9$ & $\mathrm{PL}$ & $\begin{array}{l}\text { Posterior orbital } \\
\text { cellulitis }\end{array}$ & $\begin{array}{l}\text { Left maxillary pus point on } \\
\text { examination. }\end{array}$ \\
\hline 5 & $24 / \mathrm{F}$ & $3 / 60$ & $6 / 9$ & Infiltrative & $\begin{array}{l}\text { Tuberculoma (SOL) on imaging } \\
\text { and under ATT }\end{array}$ \\
\hline
\end{tabular}

HM, Hand movement

PL, Perception of light

IC SOL, Intracranial space occupying lesion

\section{Conclusions}

The number and variety of NGON collected during just six months seems alarming. Many of them remained undiagnosed, and 13 cases had to be excluded from the study. This situation was due to inadequate data, lost follow up, probably less expertise and other causes, yet unknown. Among those who were diagnosed, blindness could have been prevented (Compressive, IIH, AION, TON, Pituitary apoplexy, Ethambutol induced optic neuropathy) in some of the cases. Early diagnosis and intervention are the key to their prevention. Whereas in others, there is no known cure or prevention (NAION, LHON) until now.

In contrast to other studies conducted in Nepal, we found NAION to be the most prevalent cause of NGON followed by; papilledema, TON, optic neuritis, IIH, and others. To the best of our knowledge, studies to detect NGON in Nepal have not been reported to date $[8,9]$. Das et al. reported 38 cases of optic neuritis in 2010 and, Rajbhandari et al. reported a case series on methanol intoxication presenting with optic neuropathy in 2008 [15,16].

Therefore, not enough studies have been conducted on NGON although some studies on optic neuropathies have been undertaken during the last decade in Nepal.

Comparing to studies conducted in India and abroad, the burden of NGON do not look different.

Chaddah et al. evaluated 100 cases of non-glaucomatous optic atrophy and showed 48 examples with primary, 41 cases with secondary and 11 cases with consecutive optic atrophy. The most frequent cause was found to be meningitis presenting either with papilledema or papillitis along with other reasons like compressive, traumatic and demyelination. No specific diagnosis could be made in 27 cases. These results showed a slightly different pattern of presentation of NGON from our study [13].

Three studies conducted in Nigeria reported a majority of NGON cases as unknown. The pattern of optic neuropathy was found as nutritional, compressive, traumatic, ischemic, inflammatory and papilledema. Olufunmilola et al. did a retrospective review of 159 cases and reported 59\% to be undiagnosed, and the commonest was compressive, whereas studies were done by Osaguona et al. and Pedreegbe et al. also reported $47 \%$ and $41.4 \%$ to be unknown, respectively. Chorioretinal diseases (24\%) and nutritional (31.3\%) was the most prevalent cause of NGON in the former and latter studies [10$12]$. 
On this regard, the data in our study looks highly contributory. The number of cases that have remained unknown in our research and those mentioned above clearly suggests the need for further studies.

We were unable to confirm the diagnosis of LHON, based on gene analysis. We had to exclude 13 patients with NGON due to lack of enough evidence. We had cases diagnosed with optic atrophy (2 unilateral and one bilateral). Further, 19 cases were grouped under papilledema (12 acute and seven chronic). The grouping was done as we could not find the underlying cause in them. These were the limitations of our study which seems consistent with the majority of other reviews as well. Importantly, causative factors for underdiagnosis has not been discussed in those studies [10-16].

The inability of the patients to pay for further investigations like; imaging and lumbar puncture (esp. to rule out IIH) and lost follow up were the primary reasons for underdiagnosis in our study. In our view, the collaborative and interdisciplinary approach may provide new insights into NGON.

There is a lack of evidence in NGON, and a majority of cases remain undiagnosed. Early diagnosis can be helpful in the prevention of blindness, and more studies are necessary to evaluate the diagnostic patterns of NGON.

The emerging burden of NGON in LMIC could not be neglected. Further research is necessary to understand the causative factors for underdiagnosis of NGON in LMIC.

\section{Ethical consideration}

The research has been approved by the ethics committee and the institutional review board of Lumbini Eye Institute, Lumbini, Nepal and has adhered to the tenets of the declaration of Helsinki. Written informed consent has been provided by the patients, or their parents or legal guardian if under the age of 18.

\section{Acknowledgment}

The Findings of this research were presented as poster at the $49^{\text {th }}$ Annual Scientific Congress of The Royal Australian and New Zealand College of Ophthalmologists in Perth. The details can be found in the following link (https://ranzcoabstracts.com/meeting-session/neuroophthalmology-poster-abstracts/).

\section{References}

1. O’Neill EC, Danesh-Meyer HV, Connell PP, Trounce IA, Coote MA, et al. (2010) The optic nerve head in acquired optic neuropathies. Nat Rev Neurol 6: 221-236. [Crossref]

2. Pérez Cambrodí RJ, Gómez Hurtado Cubillana A, Merino Suárez ML, Piñero Llorens DP, et al. (2014) Optic neuritis in the pediatric population: A review in current tendencies of diagnosis and management. J Optom 7: 125-130. [Crossref]

3. Brilliant LB, Pokhrel RP, Grasset NC, Lepkowski JM, Kolstad A, et al. (1985) Epidemiology of blindness in Nepal. Bull World Health Organ 63: 375-386. [Crossref]

4. Gurwood AS, Myers MD (2009) The diagnostic conundrums of glaucoma: cases of under- and over-diagnosed glaucoma are prevalent in the field of eye care. So, learn what you can do to reduce the number of these cases, here. Rev Optom 146: 70-78.

5. Trobe JD, Glaser JS, Cassady J, Herschler J, Anderson DR (1980) Nonglaucomatous excavation of the optic disc. Arch Ophthalmol 98: 1046-1050. [Crossref]

6. Greenfield DS (1999) Glaucomatous versus nonglaucomatous optic disc cupping clinical differentiation. Semin Ophthalmol 14: 95-108.

7. SapkotaYD (2012) The Epidemiology of Blindness in Nepal.

8. Sharma R, Marasini S, Nepal BP (2013) Pattern of blindness in a community-based hospital of Nepal. Nepal J Ophthalmol 5: 50-56. [Crossref]

9. Bajracharya K, Gautam P, Yadav SK, Shrestha N (2016) Epidemiology and causes of optic atrophy in general outpatient department of Lumbini eye institute. J Univers Coll Med Sci 3: 26-29.

10. Pedro-Egbe CN, Cookey SA, Awoyesuku EA, Ani N (2011) Nonglaucomatous optic neuropathies in Port Harcourt. Clin Ophthalmol 5: 1447-1450. [Crossref]

11. Ogun OA, Adediran OA (2014) Non-glaucomatous optic neuropathy in ibadan: extrapolations to healthcare funding in Nigeria. Ann Ib Postgrad Med 12: 103-108. [Crossref]

12. Osaguona VB, Okeigbemen VW (2015) Nonglaucomatous optic atrophy in Benin City. Ann Afr Med 14: 109-113. [Crossref]

13. Chaddah MR, Khanna KK, Chawla GD (1971) Optic atrophy (review of 100 cases). Indian J Ophthalmol 19: 172-176. [Crossref]

14. Zhang YX, Huang HB, Wei SH (2014) Clinical characteristics of nonglaucomatous optic disc cupping. Exp Ther Med 7: 995-999. [Crossref]

15. Das H, Gautam M, Lavaju P (2010) An overview of idiopathic optic neuritis in eastern Nepal. Nepal J Ophthalmol 2: 10-15. [Crossref]

16. Rajbhandari R, Acharya N, Agrawal J (2008) Methanol Poisoning: Our Experience with Recent Outbreak. Nepal J of Neuroscience 5: 75-77.

Copyright: (C2018 Pandey A. This is an open-access article distributed under the terms of the Creative Commons Attribution License, which permits unrestricted use, distribution, and reproduction in any medium, provided the original author and source are credited. 